\title{
Present status and strategy of NSAIDs-induced small bowel injury
}

\author{
Kazuhide Higuchi · Eiji Umegaki · Toshio Watanabe · \\ Yukiko Yoda · Eijiro Morita · Mitsuyuki Murano • \\ Satoshi Tokioka $\cdot$ Tetsuo Arakawa
}

Received: 14 June 2009/Accepted: 14 June 2009/Published online: 1 July 2009

(C) Springer 2009

\begin{abstract}
Non-steroidal anti-inflammatory drugs (NSAIDs) are well known to cause gastroduodenal mucosal lesions as an adverse effect. Recently, the serious problem of NSAID-induced small intestinal damage has become a topic of great interest to gastroenterologists, since capsule endoscopy and balloon enteroscopy are available for the detection of small intestinal lesions. Such lesions have been of great concern in clinical settings, and their treatment and prevention must be devised as soon as possible. The prevalence of NSAIDs-induced small intestinal injury is higher than had been expected. Recent studies show that more than $50 \%$ of patients taking NSAIDs have some mucosal damage in the small intestine. The gross appearance of NSAIDinduced enteropathy varies, appearing variously as diaphragm-like strictures, ulcers, erosions, and mucosal redness. To investigate NSAID-induced enteropathy, and to rule out other specific enteropathies, other useful methods (in addition to capsule endoscopy and balloon enteroscopy) include such modalities as radiological examination of the small intestine, the permeability test, scintigraphy or the fecal excretion test using ${ }^{111}$ Indium-labeled white blood cells, and measurement of the fecal calprotectin concentration. Diaphragm-like strictures and bleeding from mucosal breaks may be treatable with interventional enteroscopy. Misoprostol, metronidazole, and sulfasalazine are frequently used to treat NSAID-induced enteropathy, but
\end{abstract}

K. Higuchi $(\bowtie) \cdot$ E. Umegaki · Y. Yoda · E. Morita ·

M. Murano $\cdot$ S. Tokioka

2nd Department of Internal Medicine, Osaka Medical College,

Daigakumachi, Takatsuki, Osaka 569-8686, Japan

e-mail: higuchi@poh.osaka-med.ac.jp

T. Watanabe - T. Arakawa

Department of Gastroenterology, Osaka City University

Graduate School of Medicine, Osaka, Japan have undesirable effects in some cases. In the experimental model, we confirmed that several existing drugs for gastroduodenal ulcers prevented indomethacin-induced small intestinal injury. Such drugs may be useful for preventing the adverse effects of NSAIDs not only in the stomach but also in the small intestine. We hope to examine these drugs in future clinical studies.

Keywords NSAID - Aspirin - Small intestinal injury · Anti-ulcer drugs · Capsule endoscopy .

Balloon enteroscopy

\section{Introduction}

For a long time, non-steroidal anti-inflammatory drugs (NSAIDs), including aspirin, have been used frequently in clinical settings for their antipyretic, analgesic, and antiinflammatory effects. NSAIDs are thought to demonstrate such effects by the inhibition of cyclooxygenase (COX), resulting in the inhibition of prostaglandin $(\mathrm{PG})$ production at inflamed sites. But PG also has important roles in maintaining homeostasis of gastrointestinal mucosa. Thus, NSAIDs not only exhibit the expected anti-inflammatory effects but also can cause serious side effects such as gastrointestinal injury [1]. In our aging society, the use of NSAIDs has continued to increase, and their side effect of gastrointestinal mucosal injury has become a clinical problem.

Recently, the serious problem of NSAIDs-induced small intestinal damage has become a topic of great interest to gastroenterologists, since video capsule endoscopy (VCE) and balloon enteroscopy (BE) are available for the detection of small intestinal lesions [2-4]. Such lesions have been of great concern in clinical settings, and their treatment and prevention must be devised as soon as possible. We describe 
here the present status, pathology, diagnosis, prevention, and treatment of NSAIDs-induced small bowel injury.

\section{Present status of small intestinal mucosal injury caused by NSAIDs and aspirin}

In general, "diaphragm-like stricture" (Figs. 1a, 2f) is mentioned in medical textbooks as a typical NSAIDs- induced small-intestinal lesion. Since the identification of cases with NSAIDs enteropathy in the 1980s and 1990s [5-8], it has become evident that NSAIDs can damage the small intestine, resulting in a concentric "diaphragm-like stricture". However, multiple ulcers and erosions can also occur as NSAID-induced small intestinal lesions (Figs. 1,2). There are several epidemiological studies of small intestinal mucosal injury associated with NSAIDs. Morris et al. [9] used Sonde enteroscopy to examine
Fig. 1 Double-balloon enteroscopic images of small bowel injuries induced by NSAIDs. a Diaphragm-like stricture. b-d Small intestinal ulcers

Fig. 2 Video capsule endoscopic images of small bowel injuries induced by NSAIDs. a Red spot. b A small mucosal break covered with a white coating. c Large mucosal break. d Liner scar. e Scar with fold conversion. f Diaphragmlike stricture
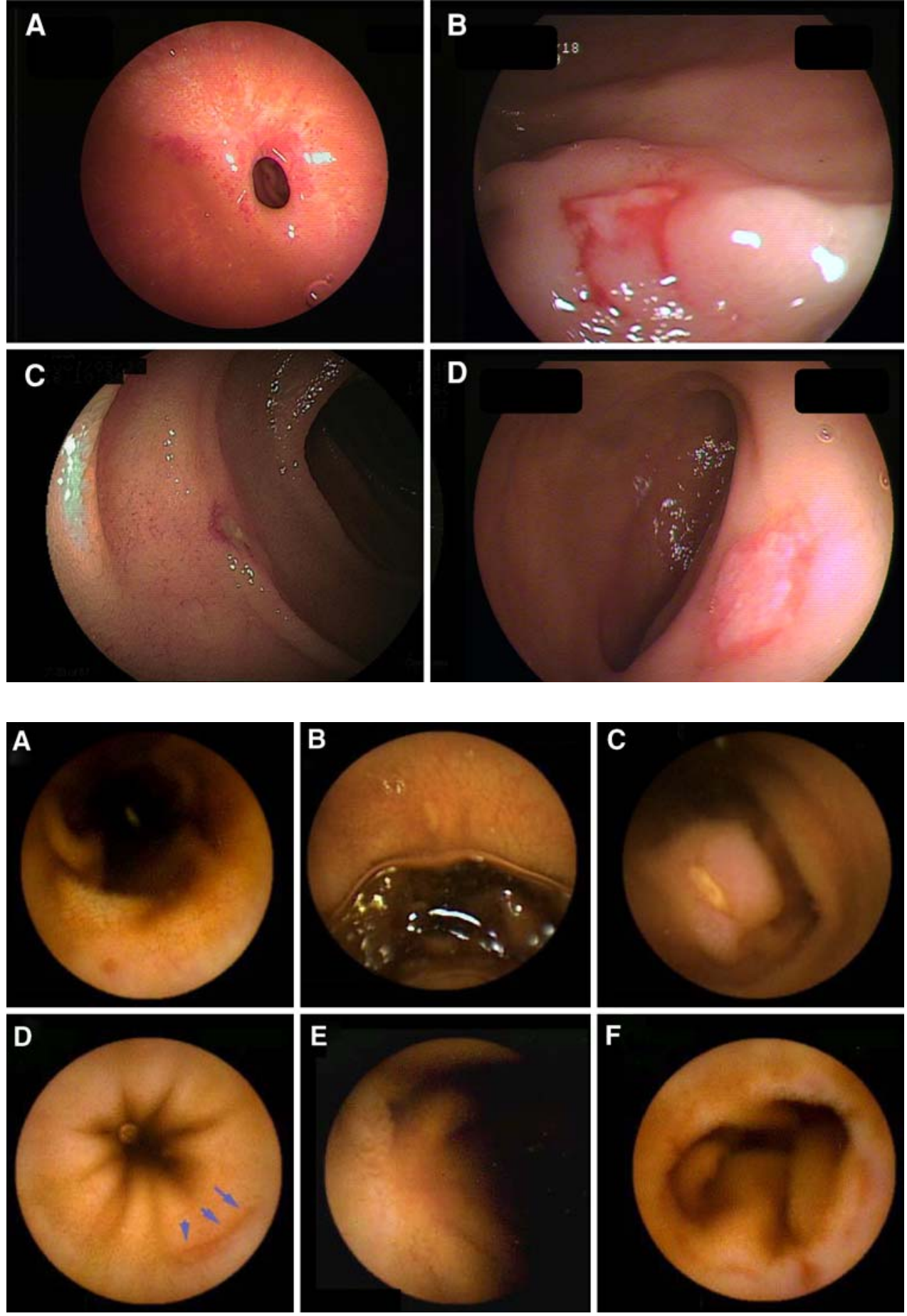
46 patients who were long-term users of NSAIDs. Small intestinal lesions were found in 19 patients $(41 \%)$. Allison et al. [1] found non-specific ulcers of the small intestine in a postmortem study. Among 464 autopsied cases that did not use NSAIDs, mucosal injuries were found in the stomach, duodenum, and small intestine in 27 cases (5.8\%), 34 cases $(7.3 \%)$, and 3 cases $(0.6 \%)$, respectively. Mucosal injuries were found in higher numbers among 249 cases that used NSAIDs: 35 cases (14.0\%), 26 cases $(10.4 \%)$, and 21 cases (8.4\%), respectively. Since VCE and BE have been available, Graham et al. [10] have performed VCE in arthritic patients who had been using NSAIDs for at least 3 months. They reported a high incidence of smallintestinal mucosal injury at $71 \%$ after NSAID administration. In Japan, Sugimori et al. [11] also performed VCE in 28 rheumatoid arthritis patients who had been using disease-modifying antirheumatic drugs or low-dose steroids for at least 1 year. They observed small bowel injuries in 13 of 16 patients (81.3\%) who used NSAIDs and in 4 of 12 patients (33.3\%) who did not. Small intestinal mucosa is speculated to be highly susceptible to injuries caused not only by NSAIDs but also by other drugs. Thus, the incidence of small-intestinal mucosal injury was clearly increased in rheumatoid arthritis patients who used NSAIDs. At our hospital (Osaka Medical College Hospital), we found that approximately $10.3 \%$ had small-bowel injuries associated with NSAIDs among patients who received VCE or BE for obscure gastrointestinal bleeding (OGIB) (Table 1), compatible with other reports [2]. With the ease of small intestine examination, we are beginning to see a relatively high incidence of small-intestinal mucosal injuries due to NSAIDs, and measures for remedying such injuries have become urgent.

It seems rational to regard aspirin as an agent that is less toxic to the small intestine in comparison with other

Table 1 Obscure gastrointestinal bleeding

\begin{tabular}{lcc}
\hline Disease & Number & Rate $(\%)$ \\
\hline NSAIDs associated & 10 & 10.3 \\
Crohn's disease & 3 & 3.1 \\
Vascular ectasia & 3 & 3.1 \\
Arteriovenous malformation & 3 & 3.1 \\
Radiation colitis & 3 & 3.1 \\
Bechet disease & 2 & 2.1 \\
Others & 7 & 7.1 \\
Except small bowel & & \\
Pancreatic bleeding & 1 & 1.0 \\
Gastroduodenal ulcers & 6 & 6.3 \\
Colon lesions & 21 & 21.6 \\
Not diagnosed & 38 & 39.1 \\
\hline
\end{tabular}

NSAIDs because other NSAIDs, but not aspirin, undergo enterohepatic recirculation [5]. Enteric-coated aspirin was originally designed to cause fewer adverse effects on the stomach even when taken for a prolonged period of time. In an attempt to decrease gastroduodenal side effects, the use of enteric-coated aspirin may have shifted the damage to the distal small bowel. In 2007, Leung et al. [12] reported on follow-up observations using VCE and found small bowel injuries in patients taking low-dose aspirin. This report has received global interest. This notion is further supported in an observational study by Lengeling et al. [13], who found 40 patients with ileal ulcers, 19 of whom had been taking enteric-coated aspirin. The Japanese Study Group for Double-Balloon Endoscopy (JSG-DBE) established a database for the practical use of DBE in the Japanese population during a 2-year period from 2004 to 2005. [14] Among 1035 patients registered in the JSE-DBE database, NSAIDs enteropathy occurred in half of the patients taking NSAIDs. Aspirin seems to be less harmful to the small intestine than NSAIDs. In 2008, Watanabe et al. [15] examined 11 gastric ulcer patients who were taking low-dose aspirin. They used VCE to examine whether or not small-intestinal lesions were present. Diffuse redness was found in $100 \%$ (11/11) of the patients, and erosions and ulcers were found in $90.9 \%$ (10/11). The very high incidence of damage might be due to the fact that their patients were restricted to individuals who had developed gastric ulcers. Pilotto et al. [16] recently reported that polymorphisms of CYP2C9, which metabolizes NSAIDs, modify the risk of NSAID-related gastroduodenal bleeding. Therefore, predisposing factors in the patient's background including genetic differences might increase the susceptibility of the small bowel to aspirin-induced damage. Taking into consideration the widespread use of aspirin in cardiovascular diseases and in cancer chemoprevention, a large-scale study in populations with different backgrounds is needed to standardize the risk for aspirin-induced mucosal damage in the small intestine, as well as in the stomach and the duodenum.

NSAIDs affect the entire gastrointestinal system and cause various abdominal symptoms such as epigastric pain, abdominal pain, constipation, and abdominal distension. In some cases, ulceration can occur in the gastrointestinal region without symptoms due to the analgesic effect of NSAIDs. In the small intestine, typical symptoms include a large amount of blood in the stool due to ulceration, anemia of unknown etiology, and symptoms of obstruction due to diaphragm-like stricture. Clinical presentation of diaphragm disease is nonspecific and may include obstructive symptoms, gastrointestinal blood loss, or abdominal pain [6, 17-19]. It is necessary to pay careful attention to these findings and symptoms in users of aspirin and other NSAIDs. 


\section{Pathogenesis of small intestinal mucosal injury caused by NSAIDs and aspirin}

PG is involved in regulation of gastrointestinal blood flow and various mucosal functions such as increasing mucus secretion. The decrease in PG production is considered to be the main cause of small bowel injuries due to NSAIDs [20-24]. In a rat study, exogenous PG administration was reported to markedly inhibit small bowel injuries induced by indomethacin, an NSAID [25].

Bjarnason et al. [23] proposed a "three hit" hypothesis as explained below. First, NSAIDs solubilize lipids of phospholipids on the mucosal surface, so the epithelial mitochondria are directly damaged. Second, the mitochondrial damage depletes intercellular energy and leads to calcium efflux and to induction of free radicals, a disruption of intercellular junctions occurs, and mucosal permeability increases in the small intestinal mucosa. Third, the mucosal barrier becomes weakened, so bile acid, proteolytic enzymes, intestinal bacteria, or toxins can easily penetrate into the epithelial cells, resulting in mucosal injury.

The involvement of the following has also been reported important in small bowel injury: the reduction of intestinal mucus due to NSAIDs, microcirculatory disturbances accompanying abnormally increased intestinal motility, NO derived from iNOS, inflammatory cytokines, neutrophil infiltration, and reactive oxygen species [26-31]. It is well that NSAIDs do not induce small-bowel injury in germ-free animals [20]. Watanabe et al. reported that lipopolysaccharides (LPS)/toll-like receptor 4 (TLR4)/ MyD88-dependent signaling pathway plays an important role in the development of such injuries [32]. Acid is closely involved in gastric mucosal injury. Similarly, small intestinal bacteria can be said to be closely involved in small-intestinal mucosal injury. These mechanisms are summarized in Fig. 3.

NSAIDs inhibit mucosal PG synthesis by inhibiting COX activity. There are two types of COX: COX-1 and COX-2. In particular, COX-1 derived PG has been considered important in maintaining homeostasis of intestinal mucosa. Previously, COX-1 inhibition alone was thought to cause a reduction of blood flow in the intestinal mucosa, microcirculatory disturbances, and increased mucosal permeability, in turn resulting in mucosal injury. In recent years, a study using an animal model has shown that smallintestinal mucosal injuries occurred only after both COX-1 and COX-2 were inhibited [33].

Regarding aspirin, animal experiments have shown that aspirin, even in large doses, do not induce mucosal damages to the stomach despite the inhibition of prostaglandin biosynthesis [34]. Furthermore, the agent has even been shown to be protective against indomethacin-induced small intestinal injury in rats, probably because of its salicylic

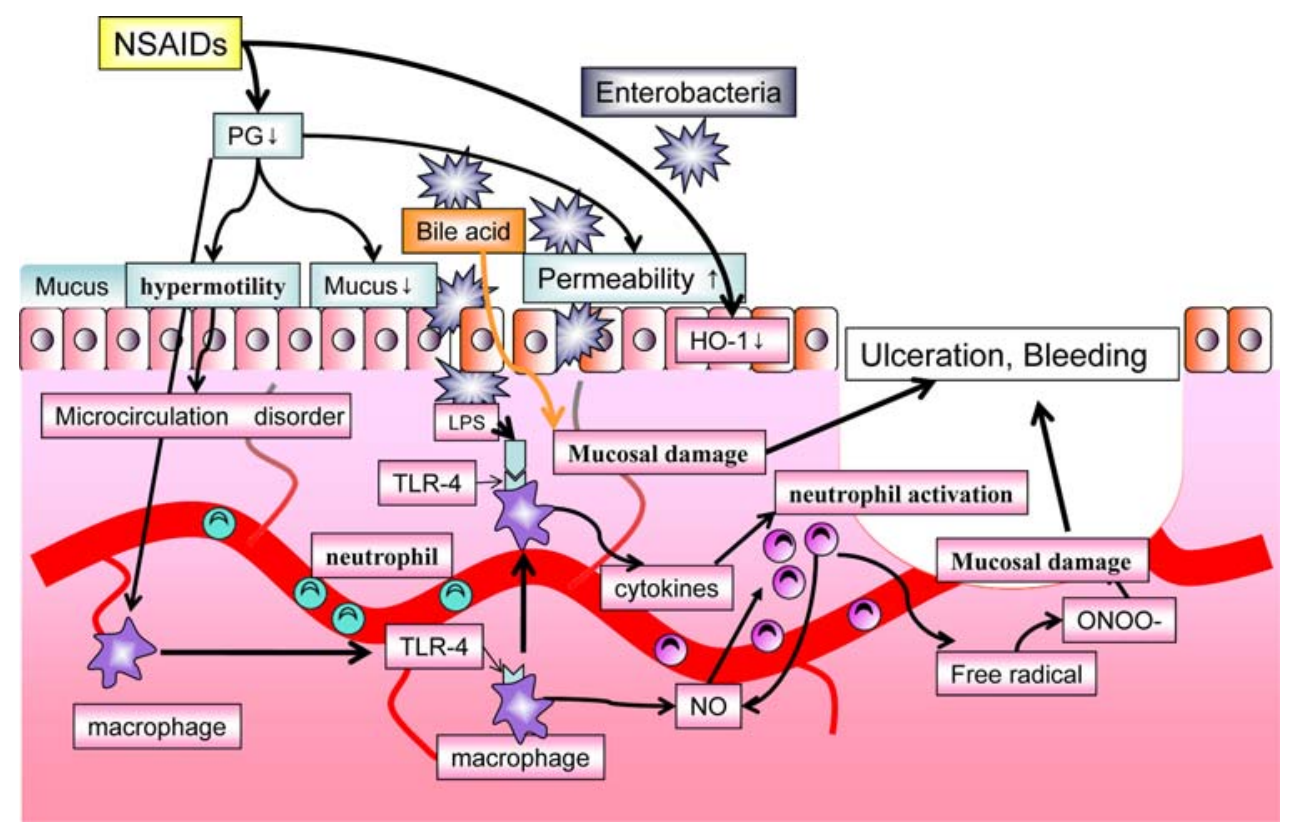

Fig. 3 Mechanisms of NSAID-induced small-bowel injury. NSAIDs decrease the mucosal endogenous PG, resulting in the reduction of intestinal mucus, microcirculatory disturbances accompanying abnormally increased intestinal motility, the disruption of intercellular junctions and increased mucosal permeability. Mucosal injuries can be caused by the penetration of bile acid, proteolytic enzymes, intestinal bacteria, or toxins. At the same time, inflammatory cytokines are induced and neutrophil infiltration occurs. In addition, a pathway mediated by lipopolysaccharide/toll-like receptor 4 plays an important role in the development of such injuries. $P G$ prostaglandin, HO- 1 heme oxygenase-1, LPS lipopolysaccharide, TLR4 tolllike receptor 4 
acid action [35]. Thus, it is impossible to cause small intestinal injuries by aspirin in experimental animals. Enteric-coated aspirin has been developed to prevent gastric damage and dissolves in the proximal small intestine, which might allow aspirin to contact the intestinal mucosa at high concentration. Enteric-coated aspirin might injure the small bowel through a topical irritant effect as well as via the inhibitory effect on COX activity. Further studies including evaluation of the intestinal toxicity of buffered aspirin are needed to support the hypothesis that the enteric-coated formulation of aspirin might be a principal cause of the damage.

\section{Diagnosis of NSAIDs-induced small intestinal injury}

The concept and documentation of the underlying disease, namely, NSAID-induced enteropathy, is largely based on measurement of small intestinal permeability and assay of surrogate markers of inflammation, such as fecal calprotectin, in stool [36]. One of the most established noninvasive measures of intestinal permeability is the use of chromium-51-labeled ethylenediaminetetraacetic acid $\left({ }^{51} \mathrm{Cr}\right.$-EDTA), which has consistently demonstrated effects of NSAIDs on the small bowel [37-39]. Measurement of inflammation is by qualitative indium-111-labeled neutrophil scintigraphy. In $50 \%$ of patients on NSAIDs for more than 6 months, this method of scintigraphy consistently shows accumulation of the labeled white cells on the terminal ileum, halted by the ileocecal valve, after $20 \mathrm{~h}$ [40]. The 4-day fecal excretion of ${ }^{111}$ In also confirms low-level inflammation in NSAID users compared to that in inflammatory bowel disease. About $60-70 \%$ of NSAID users have increased ${ }^{111}$ In excretion, which may persist for up to 16 months after discontinuing NSAIDs [40]. The ${ }^{111}$ In fecal excretion also correlates well with fecal calprotectin in NSAID-induced disease [36]. However, because of its inaccessibility, more direct assessment of the small bowel, until recently, had been limited to resected specimens or incomplete enteroscopy.

At present, VCE and BE are available for the direct detection of small intestinal lesions. The terminology of enteroscopic findings in NSAID enteropathy has not been standardized. Hayashi et al. [19] define the criteria of NSAIDs-induced small intestinal injuries: (1) history of NSAID use; (2) endoscopic findings of erosion and/or ulcer and/or typical diaphragm-like strictures; (3) improvement in clinical findings (signs and symptoms) and/or endoscopic findings by cessation of NSAIDs, except for diaphragm disease; and (4) exclusion of other causes (e.g., malignant tumor, inflammatory bowel disease, and infectious disease). However, we cannot check the improvement in endoscopic findings after cessation of NSAIDs because long-term cessation of NSAIDs is frequently impossible for patients with chronic pain or antiplatelet therapy. In the respect of endoscopic findings, those of BE in NSAIDs enteropathy have been variously described as reddish erosions [41, 42], sharply demarcated ulcers in multiplicity [41, 42], or concentric stenoses [43]. In the JSE-DBE database [14], multiple and discrete ulcers were the most frequent and they were found in $28 \%$ of patients in the NSAID group. In an interventional investigation, Maiden et al. [44] classified the VCE findings into five categories: reddened folds, denuded area, red spot, mucosal break, and blood. By means of VCE, the investigators identified mucosal breaks, which are presumed to conform to discrete ulcers of BE, in 16 of 40 volunteers (40\%) after the use of $150 \mathrm{mg} /$ day diclofenac for 2 weeks. Graham et al. [10] divided VCE findings into red spots, small erosions, large erosions, and ulcers, and they found mucosal lesions in 13 out of 21 patients $(62 \%)$ with chronic NSAIDs use. While such incidence of erosions and ulcers in the latter investigation may be a consequence of the fact that all patients had been taking non-aspirin NSAIDs, results of Matsumoto et al. [14] seem to suggest that BE is equal to VCE in the assessment of the severity of NSAIDs enteropathy.

However, the ability to detect small lesions using VCE and $\mathrm{BE}$ is not perfect. $\mathrm{BE}$ was superior to $\mathrm{VCE}$ in the diagnosis of relatively large lesions as polyps. On the other hand, small lesions such erosions and red spots were more often detected by VCE than BE [2]. In addition, we do not know which is higher, the detection ability of biomarkers or that of endoscopy. Further comparison examinations are needed in the respect of clinical usefulness.

\section{Prevention and treatment of small intestinal mucosal injury caused by NSAIDs and aspirin}

Intestinal lesions such as those described above have been of great concern in clinical settings, and their treatment and prevention must be devised as soon as possible. The mainstay of treatment for NSAID-induced injury is discontinuation of the NSAIDs. However, even if temporary cessation of the NSAIDs is possible, long-term cessation of NSAIDs is frequently impossible for patients with chronic pain or antiplatelet therapy. And long-term administration of prophylactic drugs is needed for chronic users of NSAIDs or aspirin, especially patients with experience of small intestinal bleeding. Until recently, some trials showed the efficacy of metronidazole, sulfasalazine, and misoprostol for treatment of NSAID-induced injury [4547]. However, in these studies, efficacy was indirectly evaluated by measuring several markers such as hemoglobin levels and fecal excretion of radiolabeled neutrophils, so their effectiveness has not yet been fully 
confirmed. Clinically, proton pump inhibitors (PPIs) and prostaglandin analogs are the drugs of first choice for the prevention of NSAID-induced peptic ulcers and bleeding [48]. It is useful to use such drugs as prevent the adverse effects of NSAIDs not only in the stomach but also in the small intestine. However, patients cannot continue to take misoprostol (a prostaglandin analog), since this agent frequently causes adverse effects such as diarrhea, abdominal pain, and bloating.

First, potential prevention and treatment with existing drugs for gastroduodenal ulcers must be found using data from animal experiments. We performed comprehensive screening of existing drugs for gastroduodenal ulcers and also examined the mechanisms of those effective drugs using rats (Fig. 4) [49]. Non-fasting rats were orally administered PPIs, $\mathrm{H}_{2}$ receptor antagonists, mucosal protective agents, or PG analog according to doses and schedules shown below. A PPI was administered $30 \mathrm{~min}$ before indomethacin administration: omeprazole (30, $100 \mathrm{mg} / \mathrm{kg}$ ), lansoprazole $(30,100 \mathrm{mg} / \mathrm{kg}$ ), or rabeprazole $(30,100 \mathrm{mg} / \mathrm{kg})$. The following were administered twice$30 \mathrm{~min}$ before and $6 \mathrm{~h}$ after indomethacin administration: an $\mathrm{H}_{2}$ receptor antagonist (famotidine $(3,10 \mathrm{mg} / \mathrm{kg}$ ), cimetidine $(100 \mathrm{mg} / \mathrm{kg})$, lafutidine [50] $(30 \mathrm{mg} / \mathrm{kg})$, or roxatidine [51] $(60,100,200 \mathrm{mg} / \mathrm{kg}))$; a mucosal protective agent (teprenone [52] $(100,300 \mathrm{mg} / \mathrm{kg})$, rebamipide [53] $(100,300 \mathrm{mg} / \mathrm{kg})$, irsogladine [54] $(1,10 \mathrm{mg} / \mathrm{kg})$, ecabet sodium [55] $(300 \mathrm{mg} / \mathrm{kg}))$; sucralfate $(500 \mathrm{mg} / \mathrm{kg})$ or a PG analog (misoprostol $(0.1 \mathrm{mg} / \mathrm{kg})$ ).

The following drugs significantly inhibited small bowel injuries: lansoprazole, rabeprazole, lafutidine, roxatidine, teprenone, rebamipide, irsogladine, and misoprostol. In contrast, the following drugs did not inhibit the injuries: omeprazole, famotidine, cimetidine, ecabet sodium, and sucralfate. The increase in iNOS mRNA expression and MPO activity due to indomethacin was almost completely inhibited by pretreatment with the aforementioned drugs which inhibited mucosal injuries. Next, the effects on PASpositive substances in small intestinal mucosa were examined. PAS staining increased with lafutidine, roxatidine, and irsogladine (Fig. 5) pretreatment as described in previous reports [56, 57]. These results suggest that different inhibitory mechanisms may be operating with these effective drugs.

PPI has a strong inhibitory effect on gastric acid secretion. PPI is also known to have protective effects on gastrointestinal mucosa without the inhibition of acid secretion [58-60]. Such protective effects have been reported to occur via anti-inflammatory effects such as the inhibition of IL-8 production and neutrophil infiltration and via cell injury repair through MAPK [61-63]. The previous studies also found that lansoprazole reduced NSAID-induced small-intestinal mucosal injuries as in our study [64, 65].
NSAIDs induce heme oxygenase-1 (HO-1) and this induction inhibits NSAID-dependent cell death. In addition, lansoprazole has been reported to induce HO-1[1, 66] and thus, HO-1 is thought to be involved in the inhibition of NSAID-associated small bowel injuries. Pretreatment with SnPP, an HO-1 inhibitor, aggravated small bowel injuries induced by indomethacin [67]. On the contrary, pretreatment with both lansoprazole and SnPP clearly aggravated mucosal injuries. We confirmed lansoprazole induced HO-1 in the small intestinal mucosa. These results suggest that lansoprazole, but not omeprazole, ameliorates indomethacin-induced small intestinal ulceration through upregulation of HO-1.

In the clinical studies, Goldstein et al. [68] examined healthy volunteers who were divided into three groups: celecoxib, naproxen + omeprazole, and control groups. VCE was performed, and the incidence of small-intestinal lesions was 16,55 , and $7 \%$, respectively. The results indicated that small-intestinal lesions could not be prevented by omeprazole. These results were compatible with our experimental results. Evidence of the preventive effects of PPI has already been established for NSAID-induced ulcers in areas affected by gastric acid secretion, such as in the gastroduodenal region. However, enhancement of mucosal protective action which lansoprazole, but not omeprazole, demonstrates is thought to be important in areas not affected by gastric acid, such as the small intestine. For lansoprazole, a clinical trial is needed to confirm our concept.

In another recent clinical examination of prevention using VCE, Niwa et al. [69] conducted a prospective, double-blind study using a mucosal protective agent, rebamipide, in healthy subjects. These subjects were orally administered diclofenac, omeprazole, and rebamipide for 1 week. After 4 weeks of washout, they were orally administered diclofenac, omeprazole, and placebo for 1 week. Each subject underwent video capsule endoscopy for the evaluation of small-intestinal lesions. When the subjects received a placebo, there were significantly more mucosal injuries in the small intestine, such as erosions and ulcers, compared to when they received rebamipide. Misoprostol co-therapy also reduced the incidence of small-intestinal lesions induced by a 2-week administration of diclofenac sodium in healthy subjects [70].

For aspirin-induced injury, Watanabe et al. [15] examined the therapeutic effect of misoprostol. Their subjects were patients with gastric ulcers who were orally taking low-dose, enteric-coated aspirin tablets. They were treated with PPI for 8 weeks. VCE was performed after 8 weeks, and all patients had redness and erosions in the small intestine. Misoprostol was administered instead of PPI for an additional 8 weeks. Then VCE was performed again. Small-intestinal lesions were reported to have improved. Misoprostol showed the ability to induce healing of 
Fig. 4 Small intestinal damage after indomethacin administration. a Injured mucosa stained dark blue with $1 \%$ Evans blue.

b, c Photographs of small intestinal mucosal break by stereoscopic microscope
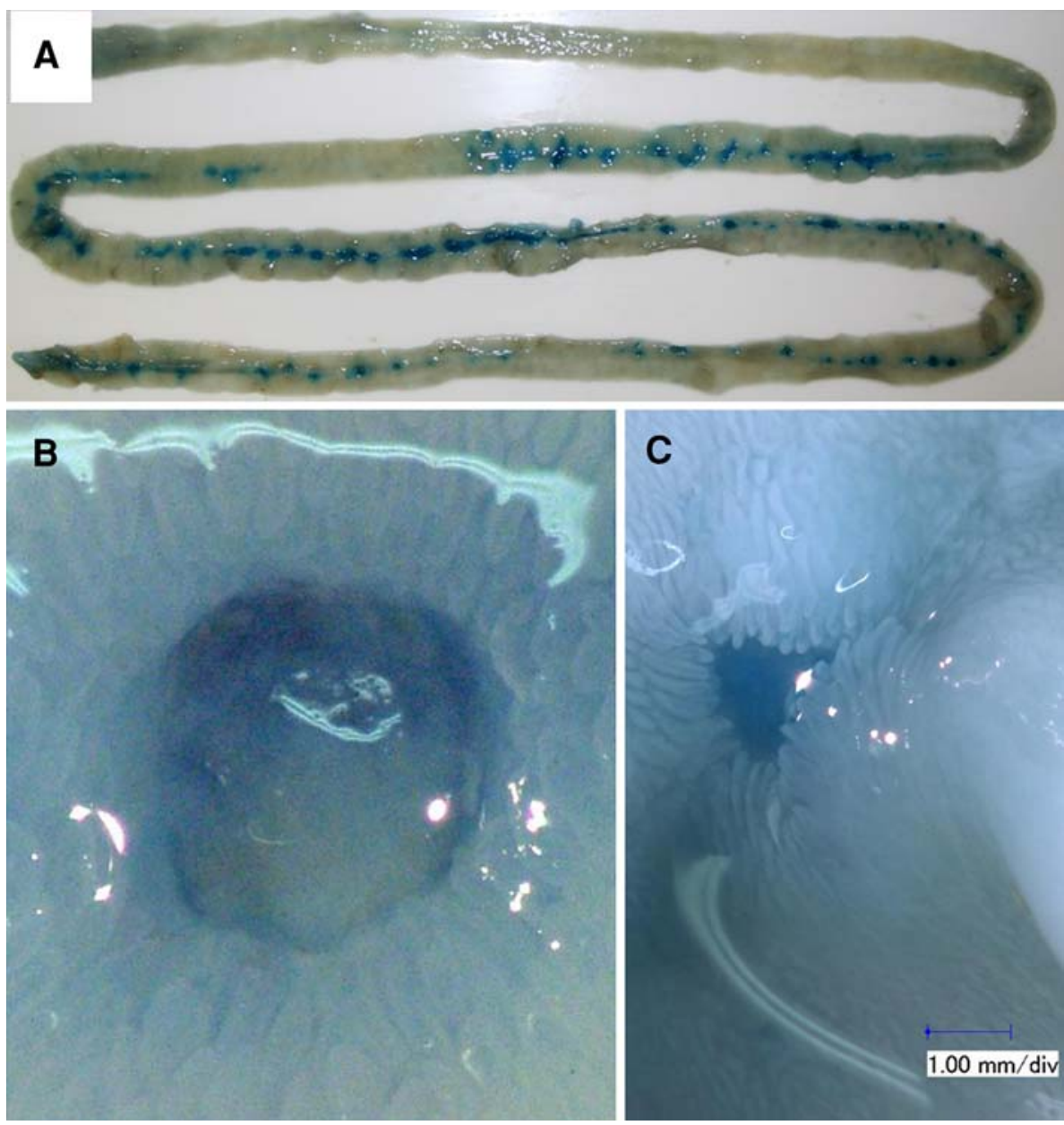
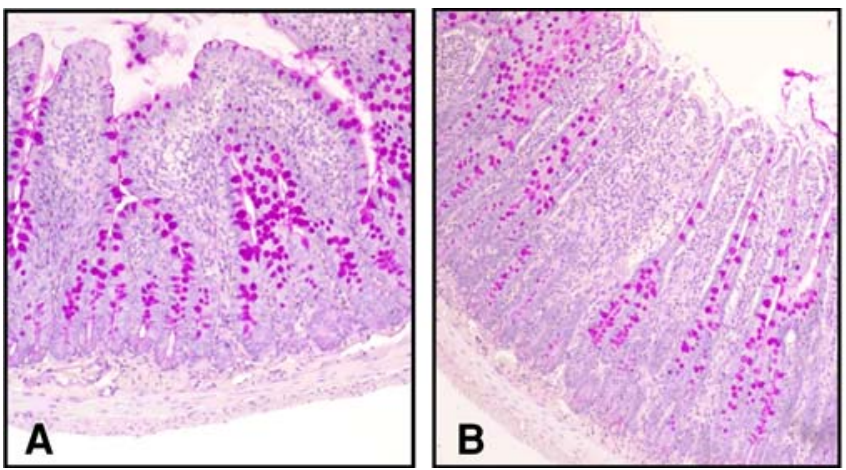

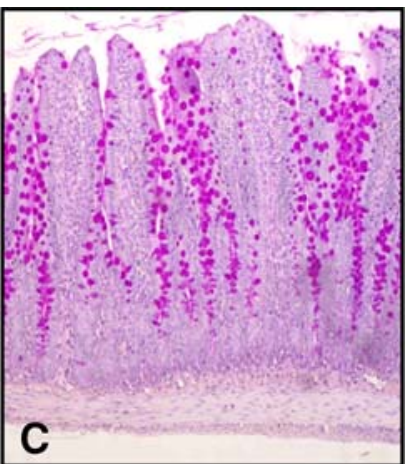

treated group than in the indomethacin-treated group. a normal mucosa, b mucosa treated with indomethacin $(10 \mathrm{mg} / \mathrm{kg}), \mathbf{c}$ mucosa treated with indomethacin $(10 \mathrm{mg} / \mathrm{kg})+$ irsogladine $(10 \mathrm{mg} / \mathrm{kg})$

in the small bowel, similar to the stomach. However, Maiden et al. [71] recently found no difference in the incidence of small intestinal injury between chronic users of traditional NSAIDs and chronic users of selective COX2 inhibitors. Furthermore, Sugimori et al. [11] also found the incidence of mucosal breaks in chronic users of preferential COX-2 inhibitors (meloxicam and etodolac) was 
high, and similar to that in traditional NSAID users. Maiden [72] speculated the reasons as following. Consequently, selective COX-2 inhibitors may not provide complete protection against some serious gastrointestinal toxicity, such as major bleeding from the lower gastrointestinal tract. The high prevalence of small bowel damage with COX-2 selective agents appears to contradict prevailing theories about the pathogenesis of NSAID-induced gastrointestinal lesions [73, 74]. That they may cause damage may seem counterintuitive as they do not inhibit COX-1 and have no topical effect, in contrast to nonselective NSAIDs. However, it should first be noted that COX-2 selective inhibitors are selective and not exclusive and thus have some COX-1 inhibitory activity also. Second, although considered inducible, COX-2 is also found constitutively in some organs and may have a regulatory role in some tissues, such as altering mucosal blood flow. Third, despite the roles of COX-1 in "housekeeping" and GI mucosal integrity and of COX-2 in inflammation, respectively, COX-1 knockout mice do not develop GI ulceration. COX-1 knockout mice live a relatively normal life and do not develop spontaneous gastrointestinal damage, whereas COX-2 knockout animals have a high mortality in their first 6 months of existence because of small bowel inflammation and perforation [75, 76]. Furthermore, although reduced gastric blood flow is seen in rats exposed to selective COX-1 inhibitors, leukocyte adherence to mesenteric venules is not affected. In contrast, COX-2 inhibition is purported to increase leukocyte adherence without altering blood flow. Only when both isoenzymes are inhibited is gastric mucosal damage seen, suggesting that both reduced mucosal blood flow and increased leukocyte adherence must occur simultaneously for damage to be initiated $[75,77]$. These points challenge the dogma that COX-1 inhibition alone causes pathology, as COX-2 may also have a role in gut integrity. Fourth, if patients are naturally low or even deficient in COX-1, then COX-2 selective inhibition will effectively be nonselective. Finally, COX-2 may have an anti-inflammatory role in the vasculature mediating cellular proliferation, adhesion molecule receptor expression, and cytokine release [78], and so its inhibition may have proinflammatory effects. Further studies with a large sample are needed to resolve whether the beneficial effects of selective COX-2 inhibitors are abolished by their long-term use.

The diaphragm-like stricture is thought to be pathognomonic of NSAID injury, and is likely a scarring reaction secondary to ulcerative injury during long-term NSAIDs use [7]. Clinical presentation of diaphragm disease is nonspecific and may include obstructive symptoms, GI blood loss, or abdominal pain [5-8]. The histological features of the diaphragm-like strictures are fibrosis in the submucosa and thickening of the muscularis mucosa [79], while the proper muscle layer is intact. Therefore, the risk of intestinal perforation with endoscopic balloon dilation therapy would be low. Endoscopic balloon dilation therapy could be an alternative to surgical intervention for diaphragm disease [19]. Diaphragm disease is now regularly visualized on VCE. However, entrapment of the capsules is common, which requires their retrieval with $\mathrm{BE}[80,81]$ or laparotomy. Intestinal resection was formerly the only option for patients with diaphragm disease in the small bowel.

\section{References}

1. Allison MC, Howatson AG, Torrance CJ, Lee FD, Russell RI. Gastrointestinal damage associated with the use of nonsteroidal antiinflammatory drugs. N Engl J Med. 1992;327(11):749-54.

2. Kameda N, Higuchi K, Shiba M, Machida H, Okazaki H, Yamagami $\mathrm{H}$, et al. A prospective, single-blind trial comparing wireless capsule endoscopy and double-balloon enteroscopy in patients with obscure gastrointestinal bleeding. J Gastroenterol. 2008;43(6):434-40.

3. Yamamoto H, Sekine Y, Sato H, Higashizawa T, Miyata T, Iino $\mathrm{S}$, et al. Total enteroscopy with a nonsurgical steerable doubleballoon method. Gastrointest Endosc. 2001;53:216-20.

4. Sunada K, Yamamoto H. Double-balloon endoscopy: past, present, and future. J Gastoronterol. 2009;44:1-12.

5. Bjarnason I, Price AB, Zanelli G, Smethurst P, Burke M, Gumpel $\mathrm{JM}$, et al. Clinicopathological features of nonsteroidal antiinflammatory drug-induced small intestinal strictures. Gastroenterology. 1988;94:1070-4.

6. Lang J, Price AB, Levi AJ, Burke M, Gumpel JM, Bjarnason I. Diaphragm disease: pathology of disease of the small intestine induced by non-steroidal anti-inflammatory drugs. J Clin Pathol. 1988;41:516-26.

7. Matsuhashi N, Yamada A, Hiraishi M, Konishi T, Minota S, Saito $\mathrm{T}$, et al. Multiple strictures of the small intestine after long-term non-steroidal anti-inflammatory drug therapy. Am J Gastroenterol. 1992;87:1183-6.

8. Fellows IW, Clarke JM, Roberts PF. Non-steroidal anti-inflammatory drug-induced jejuna and colonic diaphragm disease. A report of two cases. Gut. 1992;33:1424-6.

9. Morris AJ, Madhok R, Sturrock RD, Capell HA, MacKenzie JF. Enteroscopic diagnosis of small bowel ulceration in patients receiving non-steroidal anti-inflammatory drugs. Lancet. 1991;337:520.

10. Graham DY, Opekun AR, Willingham FF, Qureshi WA. Visible small-intestinal mucosal injury in chronic NSAID users. Clin Gastroenterol Hepatol. 2005;3(1):55-9.

11. Sugimori S, Watanabe T, Tabuchi M, Kameda N, Machida H, Okazaki $\mathrm{H}$, et al. Evaluation of small bowel injury in patients with rheumatoid arthritis by capsule endoscopy: effects of antirheumatoid arthritis drugs. Digestion. 2008;78:208-13.

12. Leung WK, Bjarnason I, Wong VW, sung JJ, Chan FK. Small bowel enteropathy associated with chronic low-dose aspirin therapy. Lancet. 2007;369:614.

13. Lengeling RW, Mitros FA, Brennan JA, Schulze KS. Ulcerative ileitis encountered at ileo-colonoscopy. Likely role of nonsteroidal agents. Clin Gastroenterol Hepatol. 2003;1:9-160.

14. Matsumoto $T$, Kudo $T$, Esaki $M$, Yano $T$, Yamamoto $H$, Sakamoto C, et al. Prevalence of non-steroidal anti-inflammatory drug-induced enteropathy determined by double-balloon endoscopy: a Japanese multicenter study. Scand J Gastroenterol. 2008;43:490-6. 
15. Watanabe T, Sugimori S, Kameda N, Machida H, Okazaki H, Tanigawa $\mathrm{T}$, et al. Small bowel injury by low-dose enteric-coated aspirin and treatment with misoprostol: a pilot study. Clin Gastroenterol Hepatol. 2008;6(11):1279-82.

16. Pilotto A, Seripa D, Franceschi M, Scarcelli C, Colaizzo D, Grandone E, et al. Genetic susceptibility to nonsteroidal antiinflammatory drug-related gastroduodenal bleeding: role of cytochrome P450 2C9 polymorphisms. Gastroenterology. 2007; 133:465-71.

17. Kelly ME, McMahon LE, Jaroszewski DE, Yousfi MM, DePetris G, Swain JM. Small bowel diaphragm disease: seven surgical cases. Arch Surg. 2005;140:22-1162.

18. Onwudike M, Sundaresan M, Melville D, Wood JJ. Diaphragm disease of the small-bowel: a case report and literature review. Did Surg. 2002;19:410-3.

19. Hayashi Y, Yamamoto H, Takauchi H, Sunada K, Miyata T, Yano $\mathrm{T}$, et al. Nonsteroidal anti-inflammatory drug-induced small-bowel lesions indentified by double-balloon endoscopy: endoscopic features of the lesions and endoscopic treatments for diaphragm disease. J Gastroenterol. 2009; 44 (Suppl XIX):57-63.

20. Robert A, Asano T. Resistance of germ-free rats to indomethacininduced intestinal inflammation. Prostaglandins. 1977;14:333-41.

21. Fang WF, Broughton A, Jacobson ED. Indomethacin induced intestinal inflammation. Am J Dig Dis. 1977;22:749-60.

22. Whittle BJ. Temporal relationship between cyclooxygenase inhibition, as measured by prostacyclin biosynthesis, and the gastrointestinal damage induced by indomethacin in the rat. Gastroenterology. 1981;80:94-8.

23. Bjarnason I, Hayllar J, MacPherson AJ, Russell AS. Side effects of nonsteroidal anti-inflammatory drugs on the small intestine in humans. Gastroenterology. 1993;104:1832-47.

24. Yamada T, Deitch E, Specian RD, Perry MA, Sartor RB, Grisham MB. Mechanisms of acute and chronic intestinal inflammation induced by indomethacin. Inflammation. 1993;17: 641-62.

25. Kunikata T, Araki H, Takeeda M, Kato S, Takeuchi K. Prostaglandin $\mathrm{E}$ prevents indomethacin-induced gastric and intestinal damage through EP receptor subtypes. J Physiol Paris. 2001;95:157-63.

26. Takeuchi K, Miyazawa T, Tanaka A, Kato S, Kunikata T. Pathogenic importance of intestinal hypermotility in NSAIDinduced small intestinal damage in rats. Digestion. 2002;66:3041.

27. Whittle BJR, Laszlo F, Evans SM, Moncada S. Induction of nitric oxide synthase and microvascular injury in the rat jejunum provoked by indomethacin. Br J Pharmacol. 1995;116:2286-90.

28. Konaka A, Tanaka A, Kato S, Nishijima M, Takeuchi K. Nitric oxide, superoxide radicals and mast cells in pathogenesis of indomethacin-induced intestinal lesions in rats. J Pharmacol Physiol. 1999;50:25-38.

29. Tanaka A, Kunihata T, Konaka A, et al. Dual action of nitric oxide in pathogenesis of indometachin-induced small intestinal ulceration in rats. J Physiol Pharmacol. 1999;50:405-17.

30. Boughton-Smith NK, Evans SM, Laszlo F, Whittle BJ, Moncada $\mathrm{S}$. The induction of nitric oxide synthase and intestinal vascular permeability by endotoxin in the rat. $\mathrm{Br} \mathrm{J}$ Pharmacol. 1993;110:1189-95.

31. Reuter BK, Davies NM, Wallace JL. Nonsteroidal anti-inflammatory drug enteropathy in rats: role of permeability, bacteria, and enterohepatic circulation. Gastroenterology. 1997;112:109-17.

32. Watanabe T, Higuchi K, Kobata A, Nishio H, Tanigawa T, Shiba $\mathrm{M}$, et al. Non-steroidal anti-inflammatory drug-induced small intestinal damage is Toll-like receptor 4 dependent. Gut. 2008; 57:181-7.

33. Sigthorsson G, Simpson RJ, Walley M, Anthony A, Foster R, Hotz-Behoftsitz C, et al. COX-1 and 2, intestinal integrity, and pathogenesis of nonsteroidal anti-inflammatory drug enteropathy in mice. Gastroenterology. 2002;122:1913-23.

34. Ligumsky M, Golanska EM, Hansen DG, Kauffman GL. Aspirin can inhibit gastric mucosa cyclo-oxygenase without causing lesions in rat. Gastroenterology. 1983;84:756-61.

35. Takeuchi K, Hase S, Mizoguchi H, Komoike Y, Tanaka A. Protection by aspirin of indomethacin-induced small intestinal damage in rats. Mediation by salicylic acid. J Physiol Paris. 2001;95:51-7.

36. Tibble JA, Sigthorson G, Foster R, Scott D, Fagerhol MK, Roseth A, et al. High prevalence of NSAID enteropathy as shown by a simple faecal test. Gut. 1999;45:362-6.

37. Bjarnason I, Smethurst P, Fenn CG, Lee CE, Menzies IS, Levi AJ, et al. Misoprostol reduces indomethacin-induced changes in human small intestinal permeability. Dig Dis Sci. 1989;34:407-11.

38. Davies GR, Rampton DS. The pro-drug sulindac may reduce the risk of intestinal damage associated with the use of conventional non-steroidal anti-inflammatory drugs. Aliment Pharmacol Ther. 1991;5:593-8.

39. Aabakken I, Osnes M. ${ }^{51}$ Cr-Ethylenediaminetetraacetic acid absorption test. Effects of naproxen, a non-steroidal, antiinflammatory drug. Scand J Gastroenterol. 1990;25:917-24.

40. Bjarnason I, Zanelli G, Smith T, Orouse P, Williams P, DeLacey $\mathrm{G}$, et al. Nonsteroidal anti-inflammatory drug induced intestinal inflammation in humans. Gastroenterology. 1987;93:480-9.

41. Yen HH, Chen YY, Soon MS. Non-steroidal anti-inflammatory drug-associated ileal ulcers: an evaluation by double-balloon enteroscopy. Gastrointest Endosc. 2006;63:328.

42. Hayashi Y, Yamamoto H, Kita H, Sunada K, Sato H, Yano Y, et al. Non-steroidal anti-inflammatory drug-induced small bowel injuries identified by double-balloon endoscopy. World J Gastroenterol. 2003;11:4861-4.

43. Kamata $\mathrm{Y}$, Iwamoto $\mathrm{M}$, Nara $\mathrm{H}$, Kamimura T, Takayashiki N, Yamamoto $\mathrm{H}$, et al. A case of rheumatoid arthritis with protein losing enteropathy induced by multiple diaphragmatic stricture of the small intestine. Successful treatment by bougieing under double-balloon enteroscopy. Gut. 2006;55:1372.

44. Maiden L, Thjodleifsson B, Theodors A, Gonzalez J, Bjarnason I. A quantitative analysis of NSAID-induced small bowel pathology by capsule enteroscopy. Gastroenterology. 2005;128:1172-8.

45. Bjarnason I, Hayllar J, Smethurst P, Price A, Gumpel MJ. Metronidazole reduces intestinal inflammation and blood loss in non-steroidal anti-inflammatory drug induced enteropathy. Gut. 1992;33:1204-8.

46. Hayllar J, Smith T, Macpherson A, Price AB, Gumpel M, Bjarnason I. Nonsteroidal anti-inflammatory drug-induced small intestinal inflammation and blood loss: effects of sulfasalazine and other disease-modifying antirheumatic drugs. Arthritis Rheum. 1994;37:1146-50.

47. Morris AJ, Murray L, Sturrock RD, et al. Short report: the effect of misoprostol on the anaemia of NSAID enteropathy. Aliment Pharmacol Ther. 1994;8:343-6.

48. Hawkey CJ, Karrasch JA, Szczepañski L, Walker DG, Barkun A, Swannell AJ. et al. Omeprazole compared with misoprostol for ulcers associated with nonsteroidal anti-inflammatory drugs. Omeprazole versus Misoprostol for NSAID-induced Ulcer Management (OMNIUM) study Group. N Engl J Med. 1998; 338:727-34.

49. Yoda Y, Takeuchi K, Kato S, Amagase K, Umegaki E, Tokioka $\mathrm{S}$, et al. Search for Prophylactic Drugs against NSAID-Induced small Intestinal lesions in Rats. Gastroenterology 2008;134(4): supplement 1, A-528.

50. Higuchi K, Watanabe T, Tominaga K, Shiba M, Nakagawa K, et al. Lafutidine can improve the quality of gastric ulcer healing in humans: a randomized controlled multicenter trial. Inflammopharmacology. 2006;14(5-6):226-30. 
51. Müller P, Jackisch P, Simon B. Comparison of the protective effects of roxatidine and misoprostol on diclofenac gastroduodenal pathology. An endoscopic, controlled study of volunteers. Arzneimittelforschung. 1994;44:1127-9.

52. Suemasu S, Tanaka KI, Namba T, Ishihara T, Katsu T, Fujimoto M, Adachi H, Sobue G, Takeuchi K, Nakai A, Mizushima T. A role for HSP70 in protecting against indomethacin-induced gastric lesions. J Biol Chem. 2009 May 13. [Epub ahead of print].

53. Park SH, Cho CS, Lee OY, Jun JB, Lin SR, Zhou LY, et al. Comparison of prevention of NSAID-induced gastrointestinal complications by rebamipide and misoprostol: a randomized, multicenter, controlled trial-STORM. Clin Biochem Nutr. 2007;40(2):148-55.

54. Zhang X, Tajima K, Kageyama K, Kyoi T. Irsogladine maleate suppresses indomethacin-induced elevation of proinflammatory cytokines and gastric injury in rats. World $\mathrm{J}$ Gastroentrol. 2008;14(30):4784-90.

55. Koizumi W, Tanabe S, Imaizumi H, Kida M, Ohida M, Koshida $\mathrm{Y}$, et al. Inhibition of peptic ulcer relapse by ranitidine and ecabet independently of eradication of Helicobactor pylori: A prospective, controlled study versus ranitidine. HepatoGastroenterology. 2003;50:577-81.

56. Kato S, Tanaka A, Kunikata T, Umeda M, Takeuchi K. Protective effect of lafutidin against indometacin-induced intestinal ulceration in rats: relation to capsaicin-sensitive sensory neurons. Digestion. 2000;61:39-46.

57. Kamei K, Kubo Y, Kato N, Hatazawa R, Amagase K, Takeuchi K. Prophylactic effect of irsogladine maleate against indomethacin-induced small intestinal lesions in rats. Dig Dis Sci. 2008;53(10):2657-66

58. Fukuda T, Arakawa T, Shimizu Y, Ohtani K, Higuchi K, Kobayashi K. Effects of lansoprazole on ethanol-induced injury and PG synthetic activity in rat gastric mucosa. J Clin Gastroenterol. 1995;20(Suppl 2):S5-7.

59. Natale G, Lazzeri G, Lubrano V, Colucci R, Vassalle C, Fornai $\mathrm{M}$, et al. Mechanisms of gastroprotection by lansoprazole pretreatment against experimentally induced injury in rats: role of mucosal oxidative damage and sulfhydryl compounds. Toxicol Appl Pharmacol. 2004;195:1710-5.

60. Fornai M, Natale G, Colucci R, Tuccori M, Carazzina G, Antonioli L, et al. Mechanisms of protection by pantoprazole against NSAID-induced gastric mucosal damage. Naunyn Schmiedebergs Arch Pharmacol. 2005;372:79-87.

61. Wandall JH. Effect of omeprazole on neutrophil chemotaxis, super oxide production, degranulation and translocation of cytochrome b-245. Gut. 1992;33:617-21.

62. Yoshida N, Yoshikawa T, Tanaka Y, Fujita N, Kassai K, Naito Y, et al. A new mechanism for anti-inflammatory actions of proton pump inhibitors-inhibitory effects on neutrophil-endothelial cell interactions. Aliment Pharmacol Ther. 2000;14(Suppl 1):74-81.

63. Biswas K, Bandyopadhyay U, Chattopadhyay I, Varadaraj A, Ali E, Banerjee RK. A novel antioxidant and antiapoptotic role of omeprazole to block gastric ulcer through scavenging of hydroxyl radical. J Biol Chem. 2003;278:10993-1001.

64. Kuroda M, Yoshida N, Ichikawa H, Takagi T, Okuda T, Naito Y, et al. Lansoprazole, a proton pump inhibitor, reduces the severity of indomethacin-induced rat enteritis. Int J Mol Med. 2006; 17:89-93.

65. Pozzoli C, Menozzi A, Grandi D, Solenghi E, Ossiprandi MC, Zullian C, et al. Protective effects of proton pump inhibitors against indomethacin-induced lesions in the rat small intestine. Naunyn-Schmiedebergs Arch Pharmacol. 2007;374:283-91.

66. Becker JC, Grosser N, Waltke C, Schulz S, Erdmann K, Domschke W, et al. Beyond gastric acid reduction: proton pump inhibitors induce heme oxygenase-1 in gastric and endothelial cells. Biochem Biophys Res Commun. 2006;345(3):1014-21.

67. Yoda Y, Higuchi K, Takeuchi K, et al. Proton pump inhibitor (PPI), lansoprazole prevents indomethacin-induced small intestinal ulceration in rats: Involvement of Heme Oxygenase (HO)-1. Gastroenterology. 2009;136(5): Supplement 1.A-684.

68. Goldstein JL, Eisen GM, Lewis B, Gralnek IM, Zlotnick S, Fort JG, Investigators. Video capsule endoscopy to prospectively assess small bowel injury with celecoxib, naproxen plus omeprazole, and placebo. Clin Gastroenterol Hepatol. 2005;3:133-41.

69. Niwa Y, Nakamura M, Ohmiya N, Maeda O, Ando T, Itoh A, et al. Efficacy of rebamipide for diclofenac-induced small-intestinal mucosal injuries in healthy subjects: a prospective, randomized, double-blinded, placebo-controlled, cross-over study. J Gastroenterol. 2008;43(4):270-6.

70. Fujimori S, Seo T, Gudis K, Ehara A, Kobayashi T, Mitsui K, et al. Prevention of nonsteroidal anti-inflammatory drug-induced small-intestinal injury by prostaglandin: a pilot randomized controlled trial evaluated by capsule endoscopy. Gastrointest Endosc. 2009;69(7):1339-46.

71. Maiden L, Yhjodleifssion B, Seigal A, Bjarnason II, Scott D, Brigisson $\mathrm{S}$, et al. Long-term effects of nonsteroidal antiinflammatory drugs and cyclooxygenase- 2 selective agents on the small bowel; a cross-sectional capsule enteroscopy study. Clin Gastroenterol Hepatol. 2007;5:1040-5.

72. Maiden L. Capsule endoscopic diagnosis of nonsteroidal antiinflammatory drug-induces enteropathy. J Gastroenterol 2009; 44(suppl 19):64-71.

73. Vane JR. Towards a better aspirin. Nature. 1994;367:215-6.

74. Vane JR, Botting RM. Mechanism of action of anti-inflammatory drugs. Scand J Rheumatol Suppl. 1996;102:9-21.

75. Sigthorsson G, Simpson RJ, Wally M, Anthony A, Foster R, Hotz-Behoftsiz C, et al. COX-1 and 2, intestinal integrity, and pathogenesis of nonsteroidal anti-inflammatory drug enteropathy in mice. Gastroenterogy. 2002;122:1913-23.

76. Langenbach R, Morham SG, Tiano HF, Loftin CD, Ghanayem $\mathrm{BI}$, Chulada PC, et al. Prostaglandin synthase I gene disruption in mice reduced arachidonic acid-induced inflammation and indomethacin-induced gastric ulceration. Cell. 1995;83:483-92.

77. Wallance JL, McKnight W, Reuter BK, et al. NSAID-induced gastric damage in rats: requirement for inhibition of both cyclooxygenase 1 and 2. Gastroenterology. 2000;119:706-14.

78. Mitchell J, Evens T. Cyclooxygenase-2 as a therapeutic target. Inflamm Res. 1998;47(suppl 2):S88-92.

79. Matsumoto T, Iida M, Matsui T, Yao T, Watanabe H, Okabe H. Non-specific multiple ulcers of the small intestine unrelated to non-steroidal anti-inflammatory drugs. J Clin Pathol. 2004; $57: 1145-50$

80. Mehdizadch S, Lo SK. Treatment of small-bowel diaphragm disease by using double-balloon enteroscopy. Gastrointest Endosc. 2006;64:1014-7.

81. Tanaka S, Mitsui K, Shirakawa K, Tatsuguchi A, Nakamura T, Hayashi Y, et al. Successful retrieval of video capsule endoscopy retained at ileal stenosis of Crohn's disease using double-balloon endoscopy. J Gastroenterol Hepatol. 2006;21:922-3. 